\title{
Non-contiguous finished genome sequence and description of Alistipes ihumii sp. nov.
}

\author{
Anne Pfleiderer ${ }^{1+}$, Ajay Kumar Mishra ${ }^{1 \dagger}$, Jean-Christophe Lagier ${ }^{1}$, Catherine Robert ${ }^{1}$, Aurelia \\ Caputo $^{1}$, Didier Raoult ${ }^{1,2}$ and Pierre-Edouard Fournier ${ }^{1 *}$ \\ ${ }^{1}$ Aix-Marseille Université, URMITE, UM63, Faculté de médecine, Marseille, France ${ }^{2}$ King \\ Fahd Medical Research Center, King Abdul Aziz University, Jeddah, Saudi Arabia \\ * Correspondence: (pierre-edouard.fournier@univ-amud.fr) \\ †These two authors contributed equally to this work
}

Keywords: Alistipes ihumii, genome, culturomics, taxono-genomics

Alistipes ihumii strain AP11 ${ }^{\top}$ sp. nov. is the type strain of $A$. ihumii sp. nov., a new species
within the genus Alistipes. This strain, whose genome is described here, was isolated from the
fecal flora of a 21 -year-old French Caucasian female, suffering from a severe restrictive form
of anorexia nervosa since the age of 12 years. A. ihumii is a Gram-negative anaerobic bacil-
lus. Here we describe the features of this organism, together with the complete genome se-
quence and annotation. The $2,753,264$ bp long genome (one chromosome but no plasmid)
contains 2,254 protein-coding and 47 RNA genes, including 3 rRNA genes.

\section{Introduction}

Alistipes ihumii strain AP11 ${ }^{\mathrm{T}}(=$ CSUR P204 = DSM 26107) is the type strain of $A$. ihumii sp. nov. This bacterium is a Gram-negative, non-spore-forming, anaerobic and non-motile bacillus that was isolated from the stool of a 21-year-old French female suffering from anorexia nervosa, and is part of a "culturomics" study aiming at cultivating individually all species within human feces [1-3].

Prokaryotic taxonomy is episodically confronted with the advancement of methodological and conceptual innovations. The current classification methodology for prokaryotes is known as polyphasic taxonomy, and relies on a combination of phenotypic and genotypic characteristics [4]. The number of completely sequenced genomes is geometrically increasing with time, concurrently with the decrease in cost of such techniques. To date, more than 6,000 bacterial genomes have been published and approximately 25,000 genome sequencing projects have been announced [5]. We recently proposed to integrate genomic information in the taxonomic framework for the description of new bacterial species [6-27].

The genus Alistipes (Rautio et al. 2003) was created in 2003 [28] and is composed of strictly anaerobic Gram-negative rods that resemble the Bacteroides fragilis group in that most species are bile-resistant and indole-positive [29]. This genus is currently comprised of five species with validly published names, including $A$. finegoldii, $A$. putredinis [28], A. indistinctus [30], A. onderdonkii and $A$. shahii [31], to which we added three proposed new species, A. senegalensis [8], $A$. timonensis [9] and A. obesi [22].

Here we present a summary classification and a set of features for a new Alistipes species, A. ihumii sp. nov. strain AP11 ${ }^{\mathrm{T}}$ (= CSUR P204 = DSM 26107), together with the description of the complete genomic sequence and its annotation.

\section{Classification and features}

A stool sample was collected from a 21-year-old French Caucasian female suffering from severe restrictive form of anorexia nervosa since the age of 12 years. At the time of sample collection, she was hospitalized in our hospital for recent aggravation of her medical condition (BMI: $10.4 \mathrm{~kg} / \mathrm{m}^{2}$ ). The patient gave an informed and signed consent. Both this study and the assent procedure were approved by the Ethics Committee of the Institut Fédératif de Recherche IFR48, Faculty of Medicine, Marseille, France under reference 09-022. Ten other potentially new bacterial species were isolated from this patient's stool, all of which are currently being described. Microbial culturomics also enabled the isolation of several other new 
bacterial species from other stool specimens [627]. The fecal specimen was stored at $-80^{\circ} \mathrm{C}$ immediately after collection. Strain $\mathrm{AP} 11^{\mathrm{T}}$ was isolated in November 2011 after 2 days of inoculation in anaerobic blood culture bottle with the addition of $5 \mathrm{~mL}$ of thioglycolate and further inoculation on Columbia agar (BioMerieux, Marcy l'Etoile, France).

This strain exhibited a 95\% $16 \mathrm{~S}$ rRNA sequence similarity with A. indistinctus [30], the phylogenetically closest Alistipes species with a validly published name (Table 1, Figure 1), and 92\% with $A$. onderdonkii [28] and A. putredinis [31]. This value was in the range of $16 \mathrm{~S}$ rRNA sequence identities among species within the genus Alistipes that range from 90 to $95 \%$, and lower than the $98.7 \% 16 \mathrm{~S}$ rRNA gene sequence threshold recommended by Stackebrandt and Ebers to delineate a new species without carrying out DNADNA hybridization [41].

Table 1. Classification and general features of Alistipes ihumii strain $\mathrm{AP} 11^{\top}$ according to the MIGS recommendations [32]

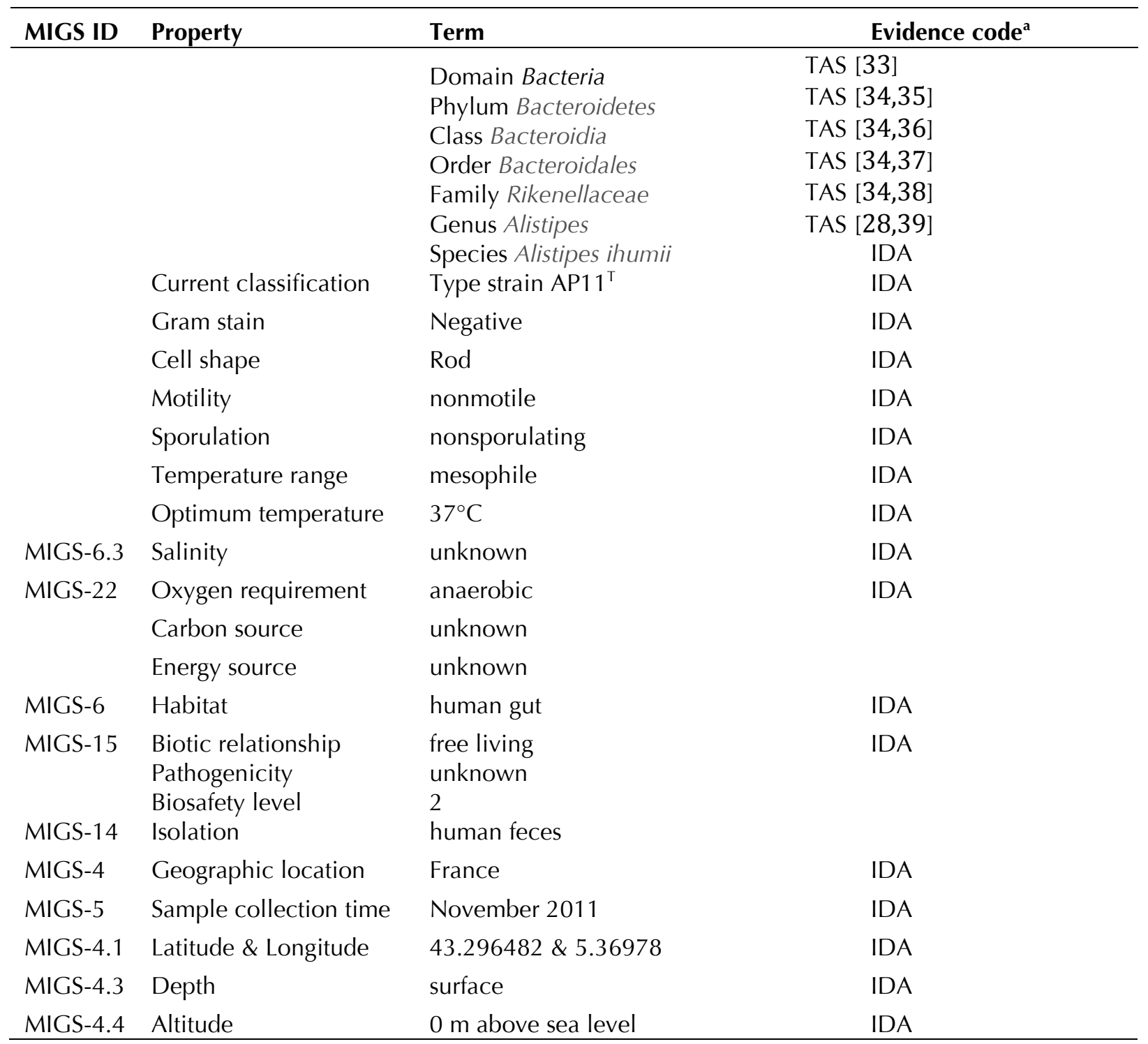

${ }^{a}$ Evidence codes - IDA: Inferred from Direct Assay; TAS: Traceable Author Statement (i.e., a direct report exists in the literature); NAS: Non-traceable Author Statement (i.e., not directly observed for the living, isolated sample, but based on a generally accepted property for the species, or anecdotal evidence). These evidence codes are from the Gene Ontology project [40]. If the evidence is IDA, then the property was directly observed for a live isolate by one of the authors or an expert mentioned in the acknowledgements. 


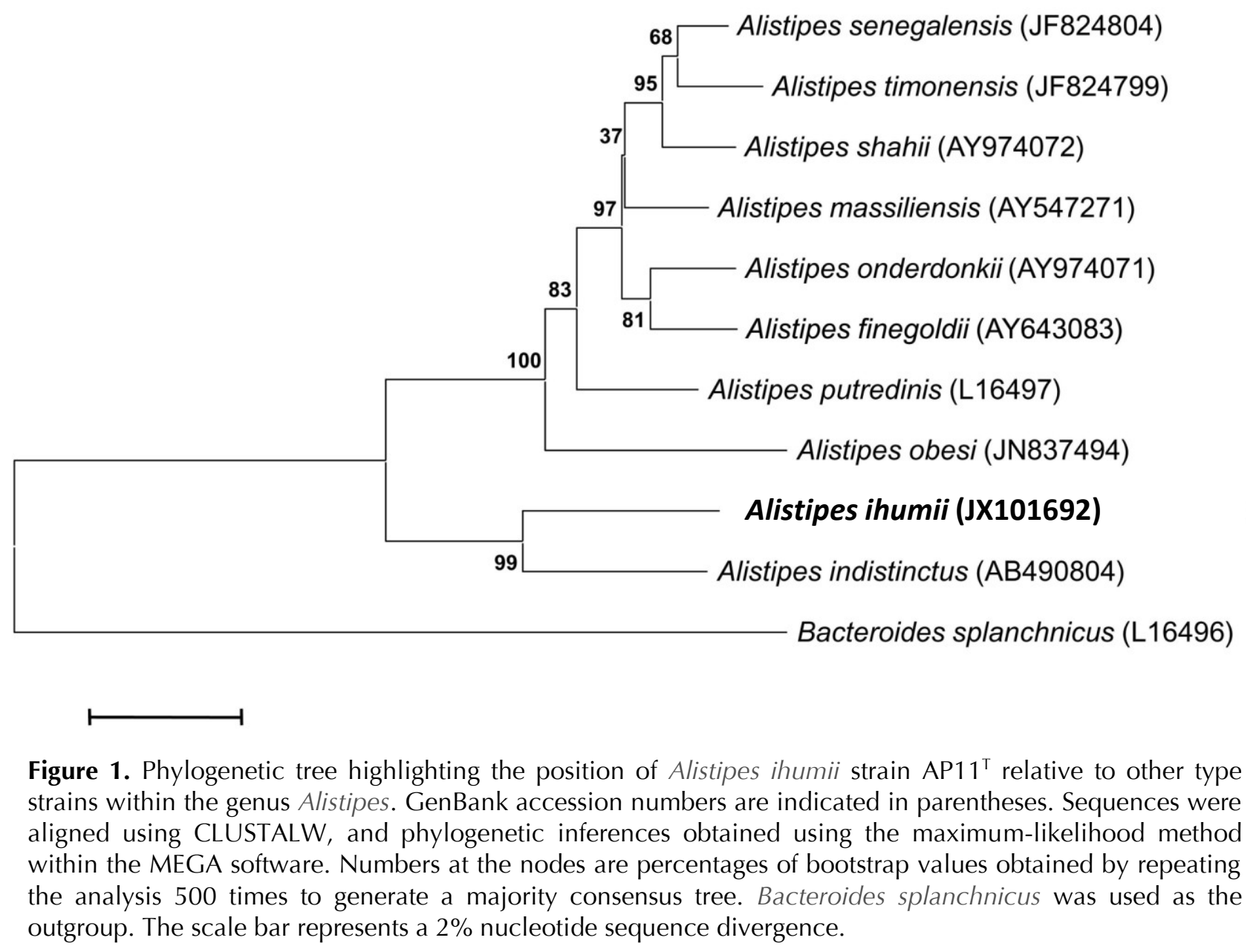

Different growth temperatures $\left(25,30,37,45^{\circ} \mathrm{C}\right)$ were tested. Growth was observed between 25 and $45^{\circ} \mathrm{C}$, with optimal growth at $37^{\circ} \mathrm{C}$ after 24 hours of inoculation. Colonies were about $0.2 \mathrm{~mm}$ in diameter, transparent, and exhibited a $B$ hemolytic activity on blood-enriched Columbia agar. Growth of the strain was tested on 5\% sheep blood agar, under anaerobic and microaerophilic conditions using the GENbag anaer and GENbag microaer systems, respectively (BioMerieux), and under aerobic conditions with or without $5 \% \mathrm{CO}_{2}$. Optimal growth of this strain was obtained anaerobically, weak growth was observed under microaerophilic conditions, and no growth was observed under aerobic atmosphere. The motility test was negative. Cells grown on agar are Gramnegative rods (Figure 2) and have mean diameter and length of 0.72 and $1.69 \mu \mathrm{m}$, respectively, as determined using electron microscopy (Figure 3). Strain $\mathrm{AP} 11^{\mathrm{T}}$ exhibited oxidase but no catalase activities. Using API 50CH (BioMérieux), we observed that strain $\mathrm{AP} 11^{\mathrm{T}}$ was asaccharolytic. Using
API 32A (BioMérieux), positive reactions were obtained for $\alpha$-glucosidase, $\beta$-glucosidase, $\mathrm{N}$-acetyl$\beta$-glucosaminidase, mannose and raffinose fermentation, alkaline phosphatase, leucyl glycine arylamidase, alanine arylamidase, and glutamyl glutamic acid arylamidase. Weak reactions were observed for $\alpha$-galactosidase and glutamic acid decarboxilase. Negative reactions were obtained for urease, arginine dihydrolase, $\beta$-galactosidase, 6 phospho- $\beta$-galactosidase, $\alpha$-arabinosidase, $\beta$ glucuronidase, $\alpha$-fucosidase, nitrate reduction, indole production, arginine arylamidase, proline arylamidase, phenylalanine arylamidase, leucine arylamidase, pyroglutamic acid arylamidase, tyrosine arylamidase, glycine arylamidase, histidine arylamidase, and serine arylamidase. A. ihumii is susceptible to amoxicillin, imipenem, and clindamycin, but resistant to vancomycin. When compared with representative species from the genus Alistipes, strain AP11 $11^{\mathrm{T}}$ exhibited the phenotypic differences detailed in Table 2. 


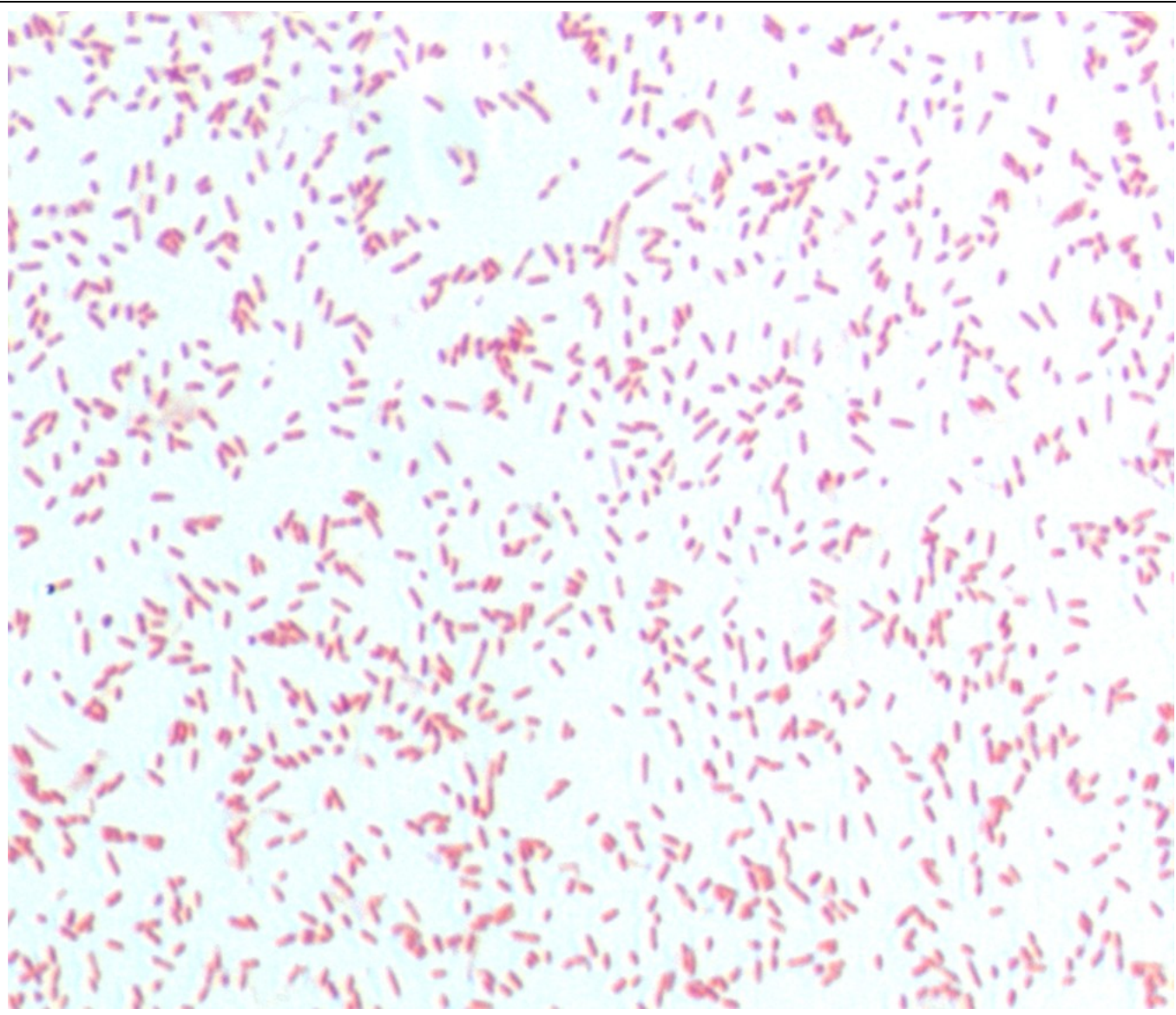

Figure 2. Gram stain of $A$. ihumii strain $\mathrm{AP} 11^{\mathrm{T}}$

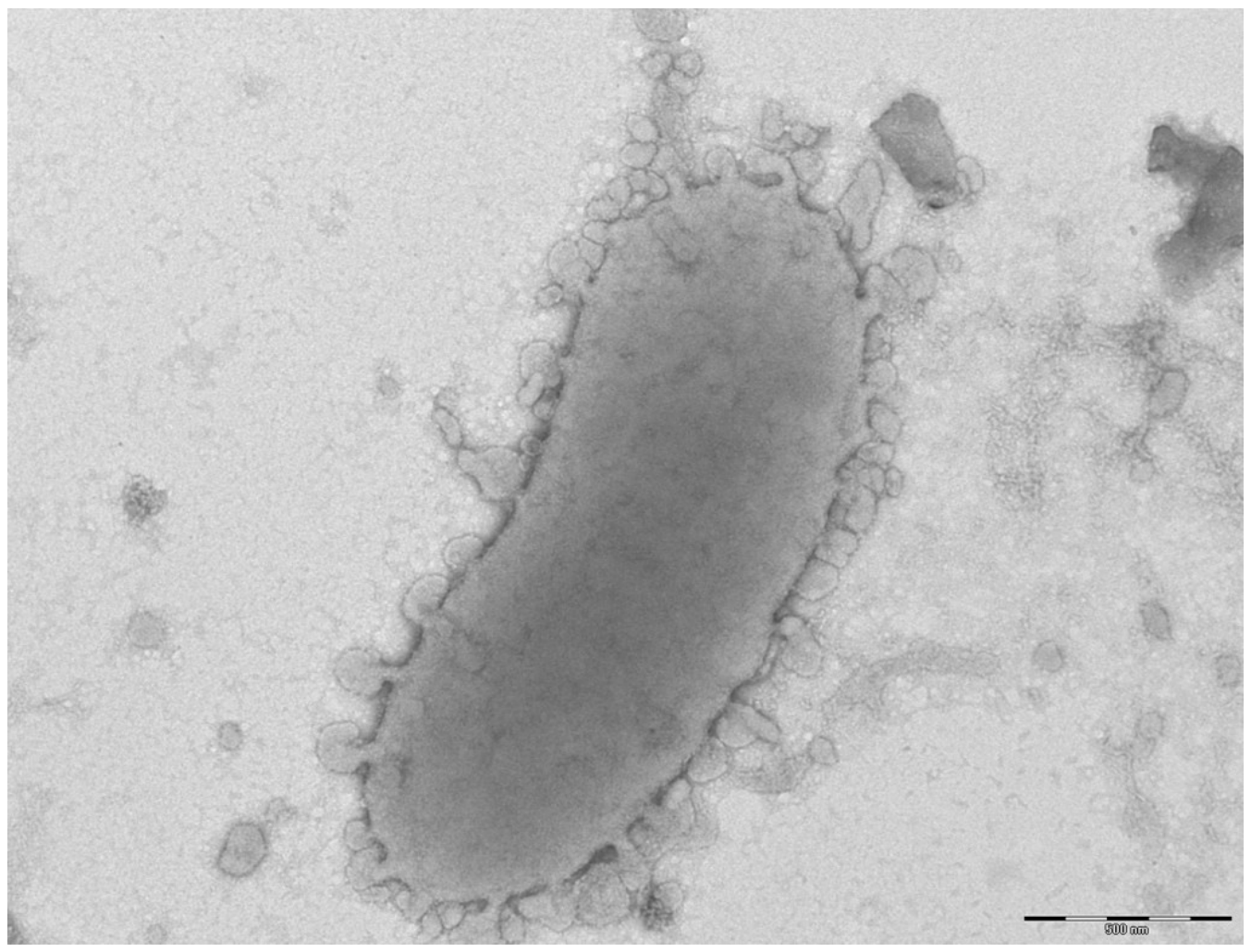

Figure 3. Transmission electron microscopy of $A$. ihumii strain $\mathrm{AP}^{2} 1^{\top}$, using a Morgani $268 \mathrm{D}$ (Philips) at an operating voltage of $60 \mathrm{kV}$. The scale bar represents $500 \mathrm{~nm}$. 
Pfleiderer et al.

Table 2. Differential characteristics of Alistipes strains ${ }^{\dagger}$

\begin{tabular}{|c|c|c|c|c|c|c|c|}
\hline Properties & A. ihumii & $\begin{array}{l}\text { A. } \\
\text { senegalensi } \\
S\end{array}$ & $\begin{array}{l}\text { A.timone } \\
\text { nsis }\end{array}$ & A.putredinis & $\begin{array}{l}\text { A.indistinc } \\
\text { tus }\end{array}$ & A.shahii & A.obesi \\
\hline Cell diameter $(\mu \mathrm{m})$ & 0.72 & 0.56 & 0.62 & 0.40 & 0.60 & 0.15 & $0.44-0.76$ \\
\hline $\begin{array}{l}\text { Oxygen require- } \\
\text { ment }\end{array}$ & anaerobic & anaerobic & $\begin{array}{l}\text { anaero- } \\
\text { bic }\end{array}$ & anaerobic & anaerobic & $\begin{array}{l}\text { anaero- } \\
\text { bic }\end{array}$ & anaerobic \\
\hline $\begin{array}{l}\text { Pigment produc- } \\
\text { tion }\end{array}$ & - & + & + & - & + & + & + \\
\hline Gram stain & - & - & - & - & - & - & - \\
\hline Salt requirement & na & + & - & - & - & - & - \\
\hline Motility & - & - & - & - & - & - & + \\
\hline $\begin{array}{l}\text { Endospore for- } \\
\text { mation }\end{array}$ & - & - & - & - & - & - & na \\
\hline $\begin{array}{l}\text { Production of } \\
\text { Alkaline phospha- } \\
\text { tase }\end{array}$ & na & na & na & + & w & + & + \\
\hline Catalase & - & + & + & + & + & - & + \\
\hline Oxidase & + & - & - & - & - & - & - \\
\hline Nitrate reductase & - & na & na & - & - & - & - \\
\hline Urease & - & na & na & - & - & + & - \\
\hline$\beta$-galactosidase & - & w & + & - & - & + & + \\
\hline $\begin{array}{l}\text { N-acetyl- } \\
\text { glucosamine }\end{array}$ & + & na & W & - & + & + & + \\
\hline Indole & - & w & W & + & - & + & - \\
\hline \multicolumn{8}{|l|}{ Activity for } \\
\hline $\begin{array}{l}\text { Leucyl glycine } \\
\text { arylamidase }\end{array}$ & + & + & + & + & - & + & + \\
\hline $\begin{array}{l}\text { Glutamic acid de- } \\
\text { carboxylase }\end{array}$ & w & na & + & + & - & - & - \\
\hline $\begin{array}{l}\text { Glycine } \\
\text { arylamidase }\end{array}$ & - & + & + & na & - & - & - \\
\hline Chymotrypsin & na & na & na & - & - & - & na \\
\hline \multicolumn{8}{|l|}{ Acid from } \\
\hline L-Arabinose & na & na & na & - & + & na & na \\
\hline Raffinose & + & na & - & - & + & + & - \\
\hline Mannose & + & + & - & - & + & + & - \\
\hline Mannitol & na & na & na & na & + & na & na \\
\hline Sucrose & na & na & na & - & + & + & na \\
\hline D-glucose & na & na & na & - & + & + & na \\
\hline D-fructose & na & na & na & - & + & + & na \\
\hline D-maltose & na & na & na & - & + & + & na \\
\hline D-lactose & na & na & na & - & + & + & na \\
\hline $\begin{array}{l}\text { Hydrolysis of gela- } \\
\text { tin }\end{array}$ & na & na & na & + & + & - & na \\
\hline $\begin{array}{l}\text { G+C content } \\
(\mathrm{mol} \%)\end{array}$ & 57.90 & 58.40 & 58.82 & 55.3 & 55.2 & 57.20 & 58.60 \\
\hline Habitat & human gut & human gut & $\begin{array}{l}\text { human } \\
\text { gut }\end{array}$ & $\begin{array}{l}\text { appendix of } \\
\text { children }\end{array}$ & human gut & $\begin{array}{l}\text { human } \\
\text { gut }\end{array}$ & human gut \\
\hline
\end{tabular}

na = data not available; $w=$ weak

${ }^{\dagger}$ Alistipes ihumii strain $\mathrm{AP} 11^{\top}$, A. senegalensis strain $\mathrm{JC} 50^{\top}$, A. timonensis strain $\mathrm{JC} 136^{\top}$, A. putredinis strain

ATCC29800 ${ }^{\top}$, A. indistinctus strain YIT12060 , A. shahii strain WAL 8301 ${ }^{\top}$, A. obesi strain ph8 ${ }^{\top}$ and A. finegoldii $\mathrm{AHN} 2437^{\mathrm{T}}$ 
Matrix-assisted laser-desorption/ionization timeof-flight (MALDI-TOF) MS protein analysis was carried out as previously described [42] using a Microflex spectrometer (Bruker Daltonics, Leipzig, Germany). Twelve individual colonies were deposited on a MTP 384 MALDI-TOF target plate (Bruker). The twelve AP $11^{\mathrm{T}}$ spectra were imported into the MALDI BioTyper software (version 2.0, Bruker) and analyzed by standard pattern matching (with default parameter settings) against the main spectra of 4,706 bacteria, including spectra from A. finegoldii, A. onderdonkii, A. shahii, $A$. senegalensis, A. obesi and A. timonensis, used as reference data in the BioTyper database. The output score enabled the presumptive identification and discrimination of the tested species from those in the database: a score $\geq 2$ with a validated species identifies a strain at the species level; and a score $<1.7$ indicates a species-level match was not made. For strain AP11', no significant score was obtained, suggesting that our isolate was not a member of any known species (Figures 4 and 5). We added the spectrum from strain $\mathrm{AP} 11^{\mathrm{T}}$ to our database.

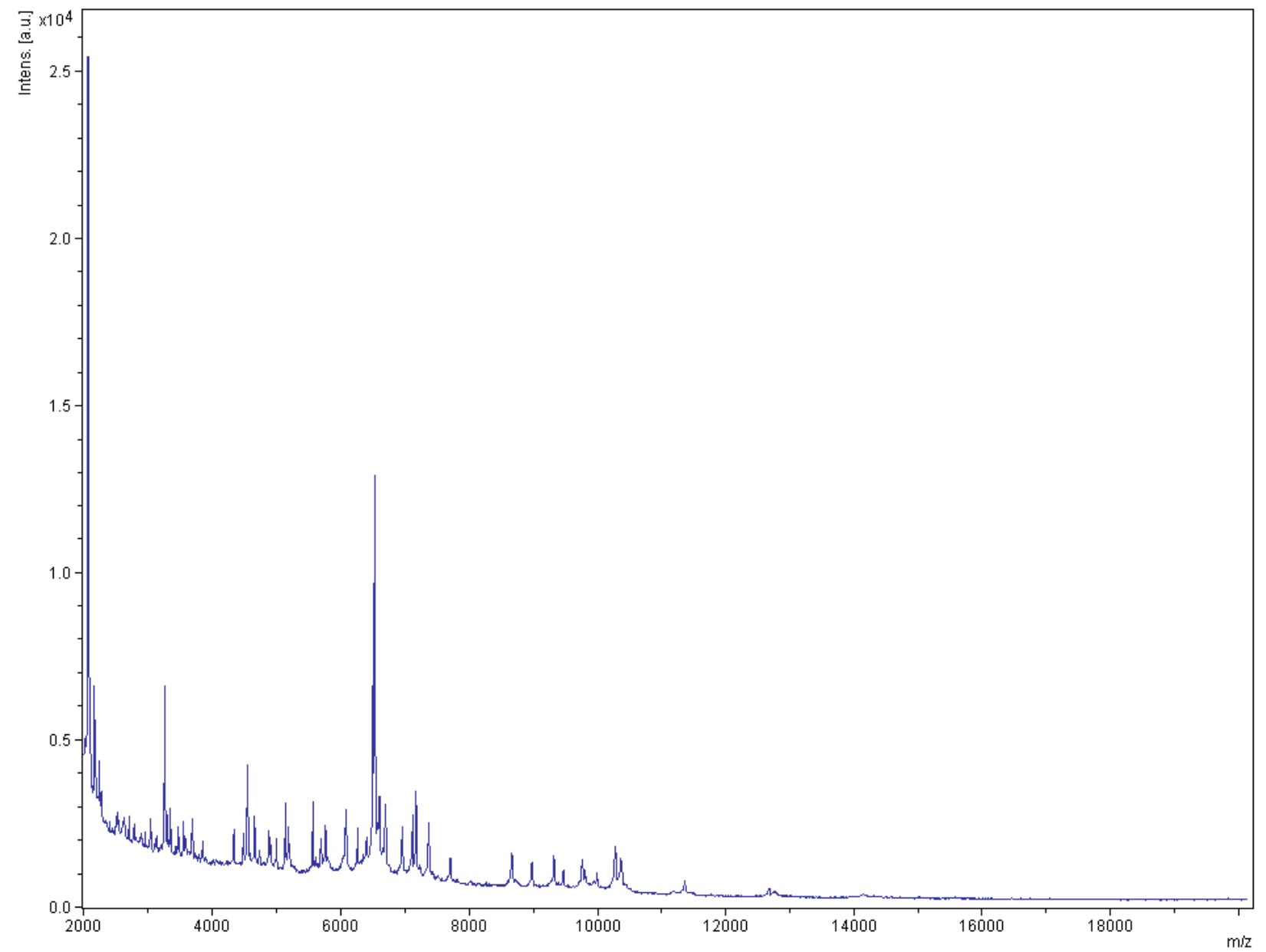

Figure 4. Reference mass spectrum from $A$. ihumii strain $\mathrm{AP}^{1} 1^{\top}$. Spectra from 12 individual colonies were compared and a reference spectrum was generated.

\section{Genome sequencing information}

\section{Genome project history}

The organism was selected for sequencing on the basis of its phylogenetic position and 16S rRNA similarity to other members of the Alistipes genus, and is part of a "culturomics" study of the human digestive flora aiming at isolating all bacterial species within human feces. It was the eighth se- quenced genome from an Alistipes species and the first from Alistipes ihumii sp. nov. A summary of the project information is shown in Table 3 . The Genbank accession number is CAPH00000000 and consists of 60 contigs. Table 3 shows the project information and its association with MIGS version 2.0 compliance [43]. 


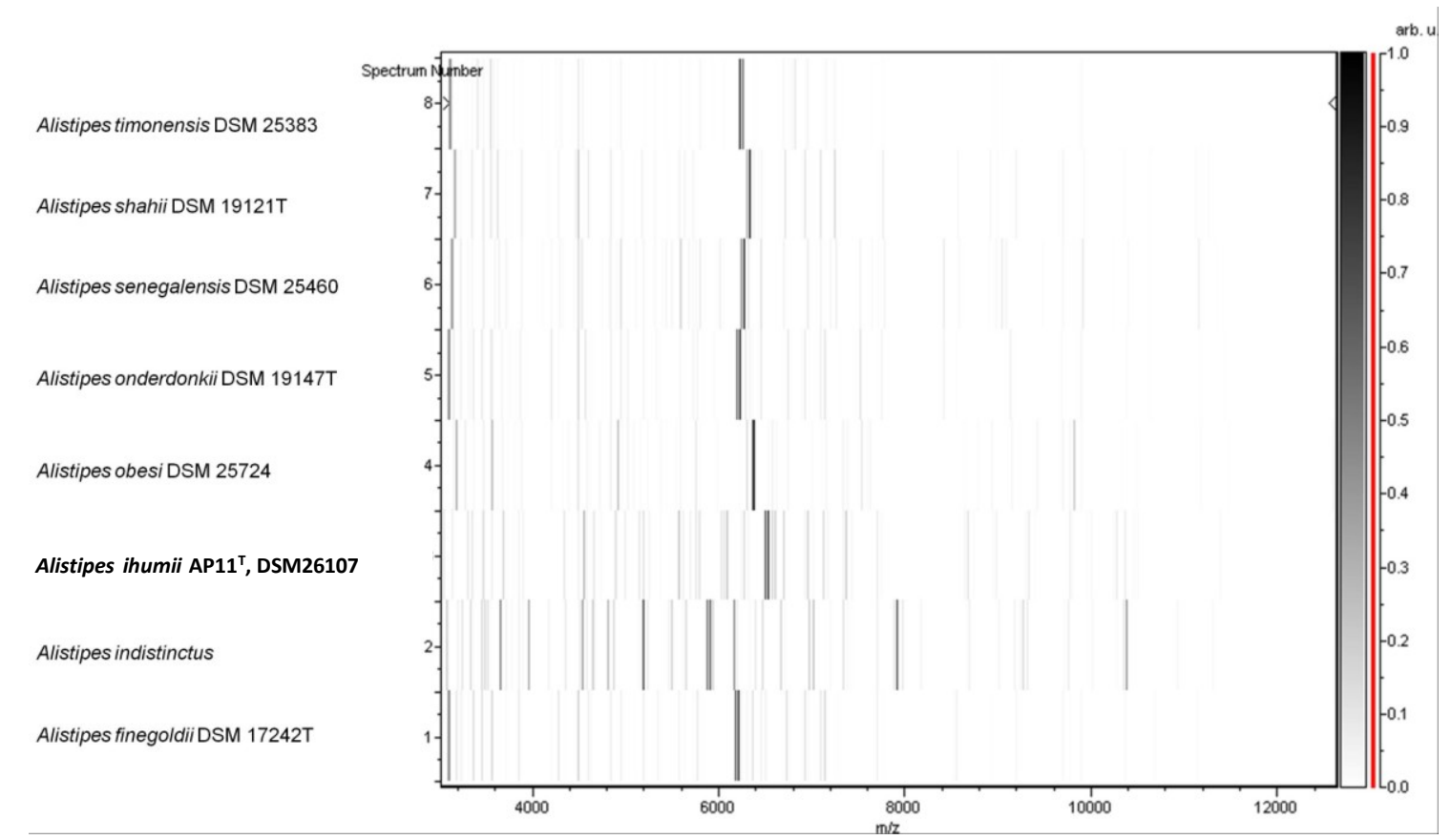

Figure 5. Gel view comparing spectra from Alistipes ihumii strain $\mathrm{AP} 11^{\top}$ and other members of the genus Alistipes (A. obesi, A. timonensis, A. senegalensis, A. shahii, A. onderdonkii and A. finegoldii). The Gel View displays the raw spectra of all loaded spectrum files arranged in a pseudo-gel like look, with each peak displayed as a band or bar. The peak intensity is reflected by the intensity of the gray color. The right $y$-axis shows the relationship between the shades of gray and the peak intensity in arbitrary units. The $x$-axis records the $\mathrm{m} / \mathrm{z}$ value. The left $y$-axis displays the running spectrum number originating from subsequent spectra loading.

Table 3. Project information

\begin{tabular}{lll}
\hline MIGS ID & Property & Term \\
\hline MIGS-31 & Finishing quality & High-quality draft \\
MIGS-28 & Libraries used & One 454 paired end 3-kb library \\
MIGS-29 & Sequencing platforms & 454 GS FLX Titanium \\
MIGS-31.2 & Fold coverage & $35 \times$ \\
MIGS-30 & Assemblers & Newbler version 2.5.3 \\
MIGS-32 & Gene calling method & Prodigal \\
& Genbank ID & CAPH00000000 \\
& Genbank Date of Release & November 28, 2012 \\
& Gold ID & Gi20720 \\
MIGS-13 & Project relevance & Study of the human gut microbiome \\
\hline
\end{tabular}

\section{Growth conditions and DNA isolation}

A. ihumii sp. nov. strain AP11T, (= CSURP204 = DSM 26107), was grown aerobically on 5\% sheep blood agar medium at $37^{\circ} \mathrm{C}$. Five Petri dishes were spread and resuspended in $3 \times 100 \mu$ l of G2 buffer (EZ1 DNA Tissue kit, Qiagen). A first mechanical lysis was performed by glass powder on the Fastprep-24 device (Sample Preparation system, MP Biomedicals, USA) for $2 \times 20$ seconds. DNA was treated with $2.5 \mu \mathrm{g} / \mu \mathrm{L}$ of lysozyme ( 30 minutes at $37^{\circ} \mathrm{C}$ ) and extracted using the BioRobot EZ 1 Advanced XL (Qiagen). The DNA was concentrated and purified on a Qiamp kit (Qiagen). The yield and the concentration of DNA was $70.7 \mathrm{ng} / \mu \mathrm{l}$ as measured by using Quant-it Picogreen kit (Invitrogen) on the Genios Tecan fluorometer.

\section{Genome sequencing and assembly}

A $3 \mathrm{~kb}$ paired-end sequencing strategy (Roche, Meylan, France) was used. DNA (5 $\mu \mathrm{g})$ was mechanically fragmented for the paired-end sequencing, using a Covaris device (Covaris Inc., Woburn, MA,USA) with an enrichment size of 3-4 kb. The DNA fragmentation was visualized through an Ag- 
ilent 2100 BioAnalyzer on a DNA Labchip 7500 which yielded an optimal size of $2.3 \mathrm{~kb}$. The library was constructed using the 454 GS FLX Titanium paired-end rapid library protocol. Circularization and nebulization were performed which generated a pattern of optimal size of $457 \mathrm{bp}$. PCR amplification was performed for 17 cycles followed by double size selection. The singlestranded paired-end library was quantified using a Quant-it Ribogreen Kit (Invitrogen) and the Genios Tecan fluorometer. The library concentration equivalence was calculated as $1.94 \times 10^{10}$ molecules $/ \mu \mathrm{L}$. The library was stored at $-20^{\circ} \mathrm{C}$ until further use.

The paired-end library was clonally amplified with 0.5 and $1 \mathrm{cpb}$ in $2 \mathrm{emPCR}$ reactions with the GS Titanium SV emPCR Kit (Lib-L) v2 (Roche). The yield of the shotgun emPCR reactions was 6.24 and $16.24 \%$ respectively for the two kinds of paired- end emPCR reactions according to the quality expected (range of 5 to 20\%) from the Roche procedure. Two libraries were loaded on the GS Titanium PicoTiterPlates (PTP Kit 70x75, Roche) and pyrosequenced with the GS Titanium Sequencing Kit XLR70 and the GS FLX Titanium sequencer (Roche). The run was performed overnight and then analyzed on the cluster through the gsRunBrowser and Newbler assembler (Roche). A total of 260,838 passed filter wells were obtained and generated $96.3 \mathrm{Mb}$ with an average length of $369 \mathrm{bp}$. The passed filter sequences were assembled using Newbler with $90 \%$ identity and 40 bp as overlap. The final assembly identified 9 scaffolds and 60 contigs ( $>1,500 \mathrm{bp}$ ) and generated a genome size of $2.75 \mathrm{Mb}$ which corresponds to a coverage of $35 \times$ genome equivalent.

\section{Genome annotation}

Open Reading Frames (ORFs) were predicted using Prodigal [44] with default parameters but the predicted ORFs were excluded if they were spanning a sequencing gap region. The predicted bacterial protein sequences were searched against the GenBank database [45] and the Clusters of Orthologous Groups (COG) databases using BLASTP. The tRNAScan-SE tool [46] was used to find tRNA genes, whereas ribosomal RNAs were found by using RNAmmer [47] and BLASTn against the GenBank database. Lipoprotein signal peptides and numbers of transmembrane helices were predicted using SignalP [48] and TMHMM [49] respectively. ORFans were identified if their BLASTP $E$-value was lower than $1 \mathrm{e}^{-03}$ for alignment length greater than 80 amino acids. If alignment lengths were smaller than 80 amino acids, we used an $E$-value of $1 \mathrm{e}^{-05}$. Such parameter thresholds have already been used in previous works to define ORFans.

Orthologous gene sets composed of one gene from A. ihumii compared to each of $A$. obesi strain ph8 (GenBank accession number CAHA00000000), A. finegoldii strain AHN 2437 (CP003274), A. indistinctus strain YIT 12060 (ADLD00000000), A. putredinis strain DSM 17216 (ABFK00000000), A. senegalensis strain JC50 ${ }^{\mathrm{T}}$ (CAHI00000000), A. shahii strain WAL 8301 (FP929032), and $A$. timonensis strain JC136 ${ }^{\mathrm{T}}$ (CAEG00000000) were identified using the Proteinortho software (version 1.4) [50] using a 30\% protein identity and an $E$-value of $1 \mathrm{e}^{-05}$. The average percentage of nucleotide sequence identity of each orthologous set was determined using the Needleman-Wunsch algorithm global alignment technique. Artemis [51] was used for data management and DNA Plotter [52] was used for visualization of genomic features. The Mauve alignment tool was used for multiple genomic sequence alignment and visualization [53].

\section{Genome properties}

The genome of $A$. ihumii strain AP11 $11^{\mathrm{T}}$ is $2,753,264$ bp long ( 1 chromosome, but no plasmid) with a $57.90 \% \mathrm{G}+\mathrm{C}$ content (Figure 6 and Table 4). Of the 2,301 predicted genes, 2,254 were proteincoding genes, and 47 were RNAs. One rRNA operon (one 16S rRNA, one 23S rRNA and one 5S rRNA) and 44 predicted tRNA genes were identified in the genome. A total of 1,465 genes $(63.66 \%)$ were assigned a putative function. Two hundred thirty-seven genes were identified as ORFans (10.29\%). The remaining genes were annotated as hypothetical proteins. The properties and the statistics of the genome are summarized in Tables 4 and 5. The distribution of genes into COGs functional categories is presented in Table 5. 


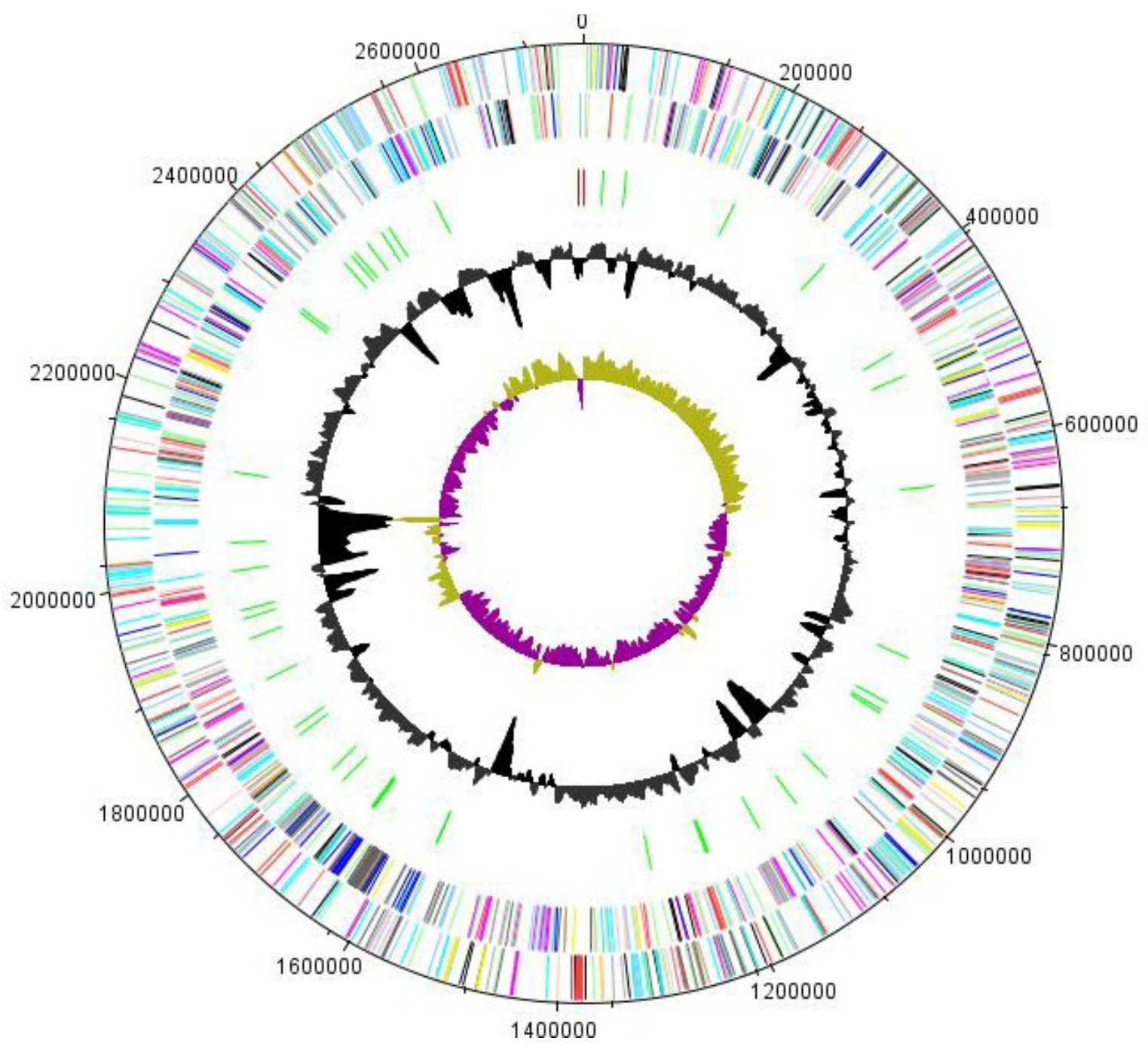

Figure 6. Graphical circular map of the chromosome. From the outside in, the outer two circles show open reading frames oriented in the forward and reverse (colored by COG categories) directions, respectively. The third circle marks the rRNA gene operon (red) and tRNA genes (green). The fourth circle shows the $\mathrm{G}+\mathrm{C} \%$ content plot. The innermost circle shows GC skew, purple and olive indicating negative and positive values, respectively.

\section{Genome comparison with other Alistipes species}

Here, we compared the genome of $A$. ihumii strain AP11 ${ }^{\mathrm{T}}$ to those of $A$. obesi strain ph8 ${ }^{\mathrm{T}}$ (GenBank accession number CAHA00000000), A. finegoldii strain AHN 2437 (CP003274), A. indistinctus strain YIT 12060 (ADLD00000000), A. putredinis strain DSM 17216 (ABFK00000000), A. senegalensis strain JC50 ${ }^{\mathrm{T}}$ (CAHI00000000), A. shahii strain WAL 8301 (FP929032), and A. timonensis strain JC136 $^{\mathrm{T}}$ (CAEG00000000). The draft genome of $A$. ihumii is larger than that of $A$. putredinis $(2.75$ and $2.55 \mathrm{Mb}$, respectively) but smaller than those of $A$. indistinctus, A. obesi, A. timonensis, A. finegoldii, A. shahii and A. senegalensis $(2.85,3.16,3.49,3.73$,
3.76, and $4.01 \mathrm{Mb}$, respectively). The $\mathrm{G}+\mathrm{C}$ content of $A$. ihumii is comparable to that of $A$. shahii (57.90 and $57.60 \%$, respectively), lower than those of A. timonensis and A. senegalensis (58.8 and $58.4 \%$, respectively) and higher than those of A. putredinis, $A$. indistinctus and $A$. finegoldii (53.30, 54.80 and $56.60 \%$, respectively). A. ihumii has a smaller gene content than those of $A$. putredinis, A. indistinctus, A. obesi, A. timonensis, $A$. shahii, A. senegalensis, and A. finegoldii $(2,301$, 2,335, 2,342, 2,619, 2,709, 3,132, 3,161, and 3,231, respectively). The ratio of genes per MB of $A$. ihumii is higher than those of $A$. timonensis, $A$. senegalensis, A. indistinctus, and A. obesi $(836,776$, 
Table 4. Nucleotide content and gene count levels of the genome

\begin{tabular}{llc}
\hline Attribute & Value & \% of total $^{\mathbf{a}}$ \\
\hline Genome size (bp) & $2,753,264$ & \\
DNA coding region (bp) & $2,320,878$ & 84.29 \\
DNA G+C content (bp) & $1,594,140$ & 57.90 \\
Number of replicons & 1 & \\
Extrachromosomal elements & 0 & 100 \\
Total genes & 2,301 & 2.04 \\
RNA genes & 47 & \\
rRNA operons & 1 & 97.95 \\
Protein-coding genes & 2,254 & 66.92 \\
Genes with function prediction & 1,540 & 63.66 \\
Genes assigned to COGs & 1,465 & 79.70 \\
Protein coding genes assigned Pfam domains & 1,834 & 12.86 \\
Genes with peptide signals & 296 & 19.86 \\
Genes with transmembrane helices & 457 & \\
CRISPR repeats & 1 & \\
\hline
\end{tabular}

${ }^{a}$ The total is based on either the size of the genome in base pairs or the total number of protein coding genes in the annotated genome

Table 5. Number of genes associated with the 25 general COG functional categories

\begin{tabular}{cccl}
\hline Code & Value & \%age $^{\text {a }}$ & Description \\
\hline J & 143 & 6.34 & Translation \\
A & 0 & 0 & RNA processing and modification \\
K & 88 & 3.90 & Transcription \\
L & 113 & 5.01 & Replication, recombination and repair \\
B & 0 & 0 & Chromatin structure and dynamics \\
D & 19 & 0.84 & Cell cycle control, mitosis and meiosis \\
Y & 0 & 0 & Nuclear structure \\
V & 28 & 1.24 & Defense mechanisms \\
T & 38 & 1.69 & Signal transduction mechanisms \\
M & 161 & 7.14 & Cell wall/membrane biogenesis \\
N & 6 & 0.27 & Cell motility \\
Z & 0 & 0 & Cytoskeleton \\
W & 0 & 0 & Extracellular structures \\
U & 32 & 142 & Intracellular trafficking and secretion \\
O & 60 & 2.66 & Posttranslational modification, protein turnover, chaperones \\
C & 111 & 4.92 & Energy production and conversion \\
G & 106 & 4.70 & Carbohydrate transport and metabolism \\
E & 131 & 5.81 & Amino acid transport and metabolism \\
F & 52 & 2.31 & Nucleotide transport and metabolism \\
H & 75 & 3.33 & Coenzyme transport and metabolism \\
I & 49 & 2.17 & Lipid transport and metabolism \\
P & 72 & 3.19 & Inorganic ion transport and metabolism \\
Q & 21 & 0.93 & Secondary metabolites biosynthesis, transport and catabolism \\
R & 235 & 10.43 & General function prediction only \\
S & 91 & 4.04 & Function unknown \\
- & 790 & 35.05 & Not in COGs \\
\hline
\end{tabular}

aThe total is based on the total number of protein coding genes in the annotated genome. 
788,821 , and 828 , respectively), comparable to that of $A$. shahii (833) and smaller than those of $A$. finegoldii and A. putredinis (866 and 915, respectively).

The average genomic nucleotide sequence identity between $A$. ihumii and other Alistipes species ranged from 70.23 to $74.37 \%$, whereas values ranged from 69.70 to $90.98 \%$ among other Alistipes species (Table 6).

However, the distribution of genes into COG categories was not entirely similar in all eight compared genomes (Figure 7).

\section{Conclusion}

On the basis of phenotypic, phylogenetic and genomic analyses, we formally propose the creation of Alistipes ihumii sp. nov. that contains strain AP $11^{\mathrm{T}}$. This bacterial strain has been isolated from the fecal flora of a patient suffering from anorexia nervosa living in Marseille, France. Several other new bacterial species were also cultivated from this patient as well as fecal samples from other patients using microbial culturomics [6-27], thus suggesting that the human fecal flora from human remains partially unknown.

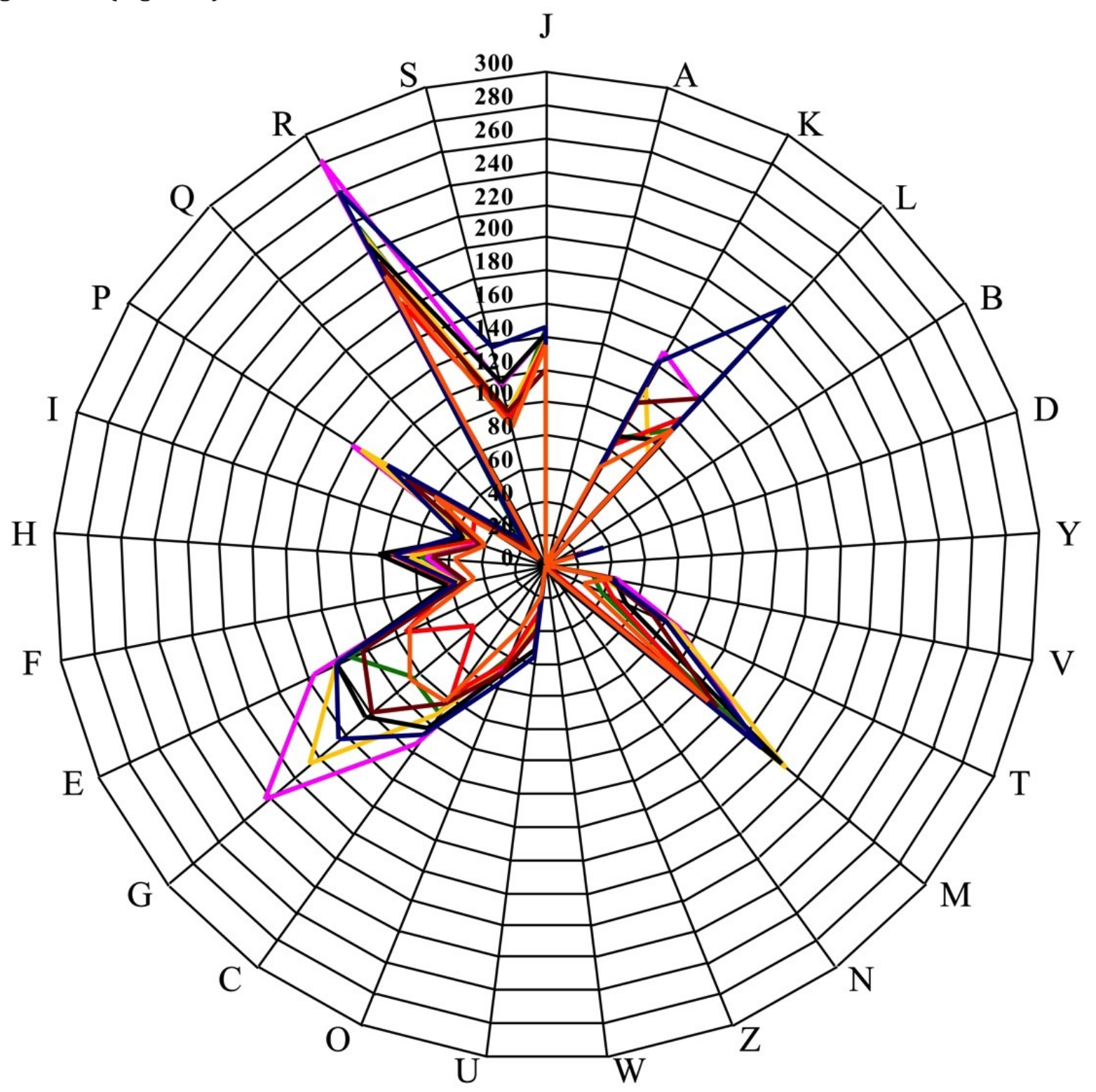

Figure 7. Distribution of functional classes of predicted genes in Alistipes ihumii (colored in green), $A$. senegalensis (pink), A. timonensis (yellow), A. shahii (brown), A. finegoldii (blue), A. putredinis (red), A. obesi (orange) and A. indistinctus (black) chromosomes according to the clusters of orthologous groups of proteins. 
Table 6. Numbers of orthologous proteins shared between genomes

\begin{tabular}{lllllllll}
\hline & AIH & ASE & AT & AS & AF & AP & AO & AIN \\
\hline A. ihumii & $\mathbf{2 , 2 5 4}$ & 1,190 & 1,164 & 958 & 1,150 & 1,055 & 1,130 & 1,147 \\
A. senegalensis & 71.16 & $\mathbf{3 , 1 6 1}$ & 1,764 & 1,739 & 1,660 & 1,277 & 1,405 & 1,218 \\
A.timonensis & 70.90 & 90.98 & $\mathbf{2 , 7 0 9}$ & 1,650 & 1,585 & 1,238 & 1,377 & 1,210 \\
A.shahii & 71.19 & 86.33 & 80.03 & $\mathbf{3 , 1 3 2}$ & 1,674 & 1,270 & 1,166 & 1,155 \\
A.finegoldii & 71.62 & 82.04 & 81.14 & 82.90 & $\mathbf{3 , 2 3 1}$ & 1,303 & 1,385 & 1,202 \\
A.putrenidis & 70.23 & 75.32 & 75.21 & 75.50 & 76.23 & $\mathbf{2 , 3 3 5}$ & 1,182 & 1,038 \\
A.onderdonkii & 71.26 & 76.42 & 76.23 & 77.06 & 76.31 & 74.45 & $\mathbf{2 , 6 1 9}$ & 1,137 \\
A.indistinctus & 74.37 & 70.02 & 70.05 & 70.00 & 69.91 & 69.70 & 69.91 & $\mathbf{2 , 3 4 2}$ \\
\hline
\end{tabular}

Upper right triangle- numbers of orthologous proteins shared between genomes; lower left triangle- average percentage of nucleotide identity between orthologous gene sets shared between genomes; bold- numbers of proteins per genome. Abbreviations: AlH- A. ihumii, ASE- A. senegalensis, AT- A. timonensis, AS- A. shahii, AF- A. finegoldii, AP- A. putredinis, AO- A. obesi, AIN- A. indistinctus

\section{Description of Alistipes ihumii sp. nov.}

Alistipes ihumii (i.hum.i'i. N.L. gen. n. ihumii, based on the acronym IHUMI, the Institut HospitaloUniversitaire Méditerranée-Infection, where the type strain was isolated).

Colonies are $0.2 \mathrm{~mm}$ in diameter and are translucent on blood-enriched Columbia agar. Cells are rod-shaped with a mean diameter of $0.72 \mu \mathrm{m}$ and a mean length of $1.69 \mu \mathrm{m}$. Optimal growth is achieved anaerobically. No growth is obtained aerobically but weak growth is observed in microaerophilic conditions. Growth occurs between $25^{\circ} \mathrm{C}$ and $45^{\circ} \mathrm{C}$, with an optimal growth observed at $37^{\circ} \mathrm{C}$.

Cells stain Gram-negative, are non motile and are asaccharolytic. Activities present are $\alpha$ glucosidase, $\beta$-glucosidase, $\mathrm{N}$-acetyl- $\beta$-glucosaminidase, mannose and rafinnose fermentation, alkaline phosphatase, leucyl glycine arylamidase, alanine arylamidase, and glutamyl glutamic acid arylamidase. Cells are negative for urease, arginine dihydrolase, $\beta$-galactosidase, 6 -phospho- $\beta$ galactosidase, $\alpha$-arabinosidase, $\beta$-glucuronidase,

\section{References}

1. Lagier JC, Armougom F, Million M, Hugon P, Pagnier I, Robert C, Bittar F, Fournous G, Gimenez G, Maraninchi M, et al. Microbial culturomics: paradigm shift in the human gut microbiome study. Clin Microbiol Infect 2012; 18:1185-1193. PubMed

2. Dubourg G, Lagier JC, Armougom F, Robert C, Hamad I, Brouqui P. The gut microbiota of a patient with resistant tuberculosis is more comprehensively studied by culturomics than by $\alpha$-fucosidase, nitrate reduction, indole production, arginine arylamidase, proline arylamidase, phenylalanine arylamidase, leucine arylamidase, pyroglutamic acid arylamidase, tyrosine arylamidase, glycine arylamidase, histidine arylamidase, and serine arylamidase. Cells are susceptible to amoxicillin, imipenem, and clindamycin, but resistant to vancomycin. The $\mathrm{G}+\mathrm{C}$ content of the genome is $57.90 \%$. The $16 \mathrm{~S}$ rRNA and genome sequences are deposited in Genbank under accession numbers JX101692 and CAPH00000000, respectively.

The type strain AP11 ${ }^{\mathrm{T}}(=$ CSUR P204 = DSM 26107) was isolated from the fecal flora of a 21year-old French Caucasian female suffering from severe anorexia nervosa.

\section{Acknowledgments}

The authors thank the Xegen Company for automating the genomic annotation process. This study was funded by the Mediterranee-Infection Foundation.

metagenomics. Eur J Clin Microbiol Infect Dis 2013; 2013:637-645.

3. Pfleiderer A, Lagier JC, Armougom F, Robert C, Vialettes B, Raoult D. Culturomics identified 11 new bacterial species from a single anorexia nervosa stool sample. [Epub ahead of print]. Eur J Clin Microbiol Infect Dis 2013.

4. Tindall BJ, Rossello-Mora R, Busse HJ, Ludwig W, Kampfer P. Notes on the characterization of pro- 
Pfleiderer et al.

karyote strains for taxonomic purposes. Int / Syst

Evol Microbiol 2010; 60:249-266. PubMed

http://dx.doi.org/10.1099/ijs.0.016949-0

5. Genome Online Database.

http://www.genomesonline.org/cgi-

bin/GOLD/index.cgi

6. Kokcha S, Mishra AK, Lagier JC, Million M, Leroy Q, Raoult D, Fournier PE. Non-contiguous finished genome sequence and description ofBacillus timonensis sp. nov. Stand Genomic Sci 2012; 6:346-355. PubMed http://dx.doi.org/10.4056/sigs.2776064

7. Lagier JC, El Karkouri K, Nguyen TT, Armougom F, Raoult D, Fournier PE. Non-contiguous finished genome sequence and description ofAnaerococcus senegalensis sp. nov. Stand Genomic Sci 2012; 6:116-125. PubMed http://dx.doi.org/10.4056/sigs.2415480

8. Mishra AK, Gimenez G, Lagier JC, Robert C, Raoult D, Fournier PE. Non-contiguous finished genome sequence and description of Alistipes senegalensis sp. nov. Stand Genomic Sci 2012; 6:304-314. http://dx.doi.org/10.4056/sigs.2625821

9. Lagier JC, Armougom F, Mishra AK, Ngyuen TT, Raoult D, Fournier PE. Non-contiguous finished genome sequence and description of Alistipes timonensis sp. nov. Stand Genomic Sci 2012; 6:315-324. PubMed http://dx.doi.org/10.4056/sigs.2685971

10. Mishra AK, Lagier JC, Robert C, Raoult D, Fournier PE. Non-contiguous finished genome sequence and description of Clostridium senegalense sp. nov. Stand Genomic Sci 2012; 6:386-395. PubMed

11. Mishra AK, Lagier JC, Robert C, Raoult D, Fournier PE. Non-contiguous finished genome sequence and description of Peptoniphilus timonensis sp. nov. Stand Genomic Sci 2012; 7:111. PubMed http://dx.doi.org/10.4056/sigs.2956294

12. Mishra AK, Lagier JC, Rivet R, Raoult D, Fournier PE. Non-contiguous finished genome sequence and description of Paenibacillus senegalensis sp. nov. Stand Genomic Sci 2012; 7:70-81. PubMed http://dx.doi.org/10.4056/sigs.3056450

13. Lagier JC, Gimenez G, Robert C, Raoult D, Fournier PE. Non-contiguous finished genome sequence and description ofHerbaspirillum massiliense sp. nov. Stand Genomic Sci 2012; 7:200-209. PubMed
14. Roux V, El Karkouri K, Lagier JC, Robert C, Raoult D. Non-contiguous finished genome sequence and description of Kurthia massiliensis sp. nov. Stand Genomic Sci 2012; 7:221-232. PubMed http://dx.doi.org/10.4056/sigs.3206554

15. Kokcha S, Ramasamy D, Lagier JC, Robert C, Raoult D, Fournier PE. Non-contiguous finished genome sequence and description ofBrevibacterium senegalense sp. nov. Stand Genomic Sci 2012; 7:233-245. PubMed http://dx.doi.org/10.4056/sigs.3256677

16. Ramasamy D, Kokcha S, Lagier JC, N'Guyen TT, Raoult D, Fournier PE. Non-contiguous finished genome sequence and description ofAeromicrobium massilense sp. nov. Stand Genomic Sci 2012; 7:246-257. PubMed http://dx.doi.org/10.4056/sigs.3306717

17. Lagier JC, Ramasamy D, Rivet R, Raoult D, Fournier PE. Non-contiguous finished genome sequence and description ofCellulomonas massiliensis sp. nov. Stand Genomic Sci 2012; 7:258-270. PubMed http://dx.doi.org/10.4056/sigs.3316719

18. Lagier JC, El Karkouri K, Rivet R, Couderc C, Raoult D, Fournier PE. Non-contiguous finished genome sequence and description ofSenegalemassilia anaerobia sp. nov. Stand Genomic Sci 2013; 7:343-356. PubMed http://dx.doi.org/10.4056/sigs.3246665

19. Mishra AK, Hugon P, Lagier JC, Nguyen TT, Robert C, Couderc C, Raoult D, Fournier PE. Noncontiguous finished genome sequence and description of Peptoniphilus obesi sp. nov. Stand Genomic Sci 2013; 7:357-369. PubMed http://dx.doi.org/10.4056/sigs.32766871

20. Mishra AK, Lagier JC, Nguyen TT, Raoult D, Fournier PE. Non-contiguous finished genome sequence and description ofPeptoniphilus senegalensis sp. nov. Stand Genomic Sci 2013; 7:370-381. PubMed http://dx.doi.org/10.4056/sigs.3366764

21. Lagier JC, El Karkouri K, Mishra AK, Robert C, Raoult D, Fournier PE. Non-contiguous finished genome sequence and description of Enterobacter massiliensis sp. nov. Stand Genomic Sci 2013; 7:399-412. PubMed http://dx.doi.org/10.4056/sigs.3396830

22. Hugon $P$, Ramasamy D, Lagier JC, Rivet R, Couderc C, Raoult D, Fournier PE. Noncontiguous finished genome sequence and description of Alistipes obesi sp. nov. Stand Ge- 
nomic Sci 2013; 7:427-439. PubMed

http://dx.doi.org/10.4056/sigs.3336746

23. Mishra AK, Hugon $P$, Robert $C$, Couderc $C$, Raoult D, Fournier PE. Non-contiguous finished genome sequence and description of Peptoniphilus grossensis sp. nov. Stand Genomic Sci 2012; 7:320-330. PubMed

24. Mishra AK, Hugon P, Nguyen TT, Raoult D, Fournier PE. Non contiguous-finished genome sequence and description of Enorma massiliensis gen. nov., sp. nov., a new member of the Family Coriobacteriaceae. Stand Genomic Sci 2013; 8:290-305. PubMed http://dx.doi.org/10.4056/sigs.3426906

25. Ramasamy D, Lagier JC, Gorlas A, Raoult D, Fournier PE. Non contiguous-finished genome sequence and description of Bacillus massiliosenegalensis sp. nov. Stand Genomic Sci 2013; 8:264-278. PubMed http://dx.doi.org/10.4056/sigs.3496989

26. Ramasamy D, Lagier JC, Nguyen TT, Raoult D, Fournier PE. Non contiguous-finished genome sequence and description of of Dielma fastidiosa gen. nov., sp. nov., a new member of the Family Erysipelotrichaceae. Stand Genomic Sci 2013; 8:336-351. PubMed http://dx.doi.org/10.4056/sigs.3567059

27. Mishra AK, Lagier JC, Robert C, Raoult D, Fournier PE. Genome sequence and description of Timonella senegalensis gen. nov., sp. nov., a new member of the suborder Micrococcinae. Stand Genomic Sci 2013; 8:318-335. PubMed http://dx.doi.org/10.4056/sigs.3476977

28. Rautio $M$, Eerola $E$, Väisänen-Tunkelrott $M L$, Molitoris D, Lawson P, Collins MD, JousimiesSomer H. Reclassification ofBacteroides putredinis (Weinberg et al., 1937) in a new genus Alistipes gen. nov., as Alistipes putredinis comb. nov., and description of Alistipes finegoldii sp. nov., from human sources. Syst Appl Microbiol 2003; 26:182-188. PubMed http://dx.doi.org/10.1078/072320203322346029

29. Tyrrell KL, Warren YA, Citron DM, Goldstein EJC. Re-assessment of phenotypic identifications of Bacteroides putredinis to Alistipes species using molecular methods. Anaerobe 2011; 17:130-134. PubMed http://dx.doi.org/10.1016/j.anaerobe.2011.04.002

30. Nagai F, Morotomi M, Watanabe $\mathrm{Y}$, Sakon H, Tanaka R. Alistipes indistinctus sp. nov. and Odoribacter laneus sp. nov., common members of the human intestinal microbiota isolated from faeces. Int J Syst Evol Microbiol 2009; 60:1296-

1302. PubMed

http://dx.doi.org/10.1099/ijs.0.014571-0

31. Song $Y$, Könönen E, Rautio M, Liu C, Bryk A, Eerola E, Finegold SM. Alistipes onderdonkii sp. nov. and Alistipes shahii sp. nov., of human origin. Int / Syst Evol Microbiol 2006; 56:19851990. PubMed http://dx.doi.org/10.1099/ijs.0.64318-0

32. 12.Field D, Garrity G, Gray T, Morrison N, Selengut J, Sterk P, Tatusova T, Thomson N, Allen MJ, Angiuoli SV, et al. The minimum information about a genome sequence (MIGS) specification. Nat Biotechnol 2008; 26:541-547.

33. Woese CR, Kandler O, Wheelis ML. Towards a natural system of organisms: proposal for the domains Archaea, Bacteria, and Eucarya. Proc Natl Acad Sci USA 1990; 87:4576-4579. PubMed http://dx.doi.org/10.1073/pnas.87.12.4576

34. Validation List No. 143. Int / Syst Evol Microbiol $2012 ; 62: 1-4$. http://dx.doi.org/10.1099/ijs.0.039487-0

35. Krieg NR, Ludwig W, Euzéby J, Whitman WB. Phylum XIV. Bacteroidetes phyl. nov. In: Krieg NR, Staley JT, Brown DR, Hedlund BP, Paster BJ, Ward NL, Ludwig W, Whitman WB (eds), Bergey's Manual of Systematic Bacteriology, Second Edition, Volume 4, Springer, New York, 2011, p. 25.

36. Krieg NR. Class I. Bacteroidia class. nov. In: Krieg NR, Staley JT, Brown DR, Hedlund BP, Paster BJ, Ward NL, Ludwig W, Whitman WB (eds), Bergey's Manual of Systematic Bacteriology, Second Edition, Volume 4, Springer, New York, 2011, p. 25.

37. Krieg NR. Order I. Bacteroidales ord. nov. In: Krieg NR, Staley JT, Brown DR, Hedlund BP, Paster BJ, Ward NL, Ludwig W, Whitman WB (eds), Bergey's Manual of Systematic Bacteriology, Second Edition, Volume 4, Springer, New York, 2011, p. 25.

38. Krieg NR, Staley JT, Brown DR, Hedlund BP, Paster BJ, Ward NL, Ludwig W, Whitman WB. Family III. Rikenellaceae fam. nov. In: Krieg NR, Staley JT, Brown DR, Hedlund BP, Paster BJ, Ward NL, Ludwig W, Whitman WB (eds), Bergey's Manual of Systematic Bacteriology, Second Edition, Volume 4, Springer, New York, 2011, p. 54.

39. Validation List no. 94. Validation of publication of new names and new combinations previously effectively published outside the IJSEM. Int J Syst Evol Microbiol 2003; 53:1701-1702. PubMed http://dx.doi.org/10.1099/ijs.0.03001-0 
Pfleiderer et al.

40. Ashburner M, Ball CA, Blake JA, Botstein D, Butler $\mathrm{H}$, Cherry JM, et al. Gene ontology: tool for the unification of biology. The Gene Ontology Consortium. Nat Genet 2000; 25:25-29. PubMed http://dx.doi.org/10.1038/75556

41. Stackebrandt E, Ebers J. Taxonomic parameters revisited: tarnished gold standards. Microbiol Today 2006; 33:152-155.

42. Seng P, Drancourt M, Gouriet F, La Scola B, Fournier PE, Rolain JM, Raoult D. Ongoing revolution in bacteriology: routine identification of bacteria by matrix-assisted laser desorption ionization time-of-flight mass spectrometry. Clin Infect Dis 2009; 49:543-551. PubMed http://dx.doi.org/10.1086/600885

43. Field D, Garrity G, Gray T, Morrison N, Selengut J, Sterk P, Tatusova T, Thomson N, Allen MJ, Angiuoli SV, et al. The minimum information about a genome sequence (MIGS) specification. Nat Biotechnol 2008; 26:541-547. PubMed http://dx.doi.org/10.1038/nbt1360

44. Prodigal. http://prodigal.ornl.gov

45. GenBank database. http://www.ncbi.nlm.nih.gov/genbank

46. Lowe TM, Eddy SR. tRNAscan-SE: a program for improved detection of transfer RNA genes in genomic sequence. Nucleic Acids Res 1997;

25:955-964. PubMed http://dx.doi.org/10.1093/nar/25.5.0955

47. Lagesen K, Hallin P, Rodland EA, Staerfeldt HH, Rognes T, Ussery DW. RNAmmer: consistent and rapid annotation of ribosomal RNA genes. Nucle- ic Acids Res 2007; 35:3100-3108. PubMed

http://dx.doi.org/10.1093/nar/gkm160

48. Bendtsen JD, Nielsen H, von Heijne G, Brunak S. Improved prediction of signal peptides: SignalP 3.0. J Mol Biol 2004; 340:783-795. PubMed http://dx.doi.org/10.1016/j.jmb.2004.05.028

49. Krogh A, Larsson B, von Heijne G, Sonnhammer EL. Predicting transmembrane protein topology with a hidden Markov model: application to complete genomes. J Mol Biol 2001; 305:567580. PubMed http://dx.doi.org/10.1006/jmbi.2000.4315

50. Lechner M, Findeib S, Steiner L, Marz M, Stadler PF, Prohaska SJ. Proteinortho: Detection of (Co)orthologs in large-scale analysis. BMC Bioinformatics $2011 ; \mathbf{1 2}: 124$. PubMed http://dx.doi.org/10.1186/1471-2105-12-124

51. Rutherford K, Parkhill J, Crook J, Horsnell T, Rice P, Rajandream MA, Barrell B. Artemis: sequence visualization and annotation. Bioinformatics 2000; 16:944-945. PubMed http://dx.doi.org/10.1093/bioinformatics/16.10.94 $\underline{4}$

52. Carver T, Thomson N, Bleasby A, Berriman M, Parkhill J. DNAPlotter: circular and linear interactive genome visualization. Bioinformatics 2009; 25:119-120. PubMed http://dx.doi.org/10.1093/bioinformatics/btn578

53. Darling AC, Mau B, Blattner FR, Perna NT. Mauve: multiple alignment of conserved genomic sequence with rearrangements. Genome Res 2004; 14:1394-1403. PubMed http://dx.doi.org/10.1101/gr.2289704 